\title{
DINÂMICA FÍSICO-HÍDRICA DE UMA TOPOSSEQÜÊNCIA DE SOLOS SOB SAVANA FLORESTADA (CERRADÃO) EM ASSIS, SP(1)
}

\author{
Carlos Eduardo Pinto Juhász ${ }^{(2)}$, Patrícia Ribeiro Cursi ${ }^{(3)}$, Miguel \\ Cooper $^{(4)}$, Thalita Campos Oliveira ${ }^{(3)}$ \& Ricardo Ribeiro Rodrigues ${ }^{(5)}$
}

\begin{abstract}
RESUMO
Este trabalho teve como objetivo a caracterização morfológica e físico-hídrica de uma toposseqüência de solos sob floresta nativa de uma parcela permanente de 320 × 320 m, instalada na Estação Ecológica de Assis (SP). A vegetação da parcela consiste em um remanescente de Savana Florestada (Cerradão) da zona limítrofe sul do grande domínio do Cerrado. O estudo da geometria bidimensional (horizontal e vertical) dos horizontes em uma toposseqüência possibilitou o detalhamento da morfologia do solo. Para estudar a dinâmica da água no ambiente de desenvolvimento das plantas nativas, foram obtidas curvas de retenção, análise granulométrica e medidas de condutividade hidráulica saturada no campo, utilizando o permeâmetro de Guelph. O monitoramento da umidade do solo in situ, utilizando o sensor WCR, e da distribuição de chuvas foi realizado no período de novembro de 2003 a novembro de 2004. Os solos foram classificados de montante a jusante em Latossolo Vermelho, Latossolo Vermelho-Amarelo, Latossolo Amarelo e Gleissolo Háplico. $\mathrm{O}$ alto teor de argila no horizonte de subsuperfície do Gleissolo, em contraste aos Latossolos com maior teor de areia, determina menor drenagem, maior retenção hídrica e baixa condutividade hidráulica nesta camada, não atingindo a saturação em nenhum momento do ano monitorado. $O$ comportamento físico-hídrico dos solos é influenciado pelas condições do relevo, evidenciado pela transição lateral contínua de cor, textura e estrutura dos solos na toposseqüência,
\end{abstract}

\footnotetext{
(1) Parte da Tese de Mestrado apresentada pelo primeiro autor ao Programa de Pós-Graduação em Solos e Nutrição de Plantas da Escola Superior de Agricultura "Luiz de Queiroz", Universidade de São Paulo - ESALQ/USP. Trabalho apresentado no XXX Congresso Brasileiro de Ciência do Solo, Recife (PE), 2005. Projeto financiado pela FAPESP. Recebido para publicação em março de 2005 e aprovado em março de 2006.

(2) Doutorando do Programa de Pós-Graduação em Solos e Nutrição de Plantas da Escola Superior de Agricultura "Luiz de Queiroz", Universidade de São Paulo - ESALQ/USP. Av. Pádua Dias 11, Caixa Postal 09, CEP 13418-900 Piracicaba (SP). Bolsista da FAPESP. E-mail: juhasz@esalq.usp.br

(3) Graduando em Engenharia Agronômica, ESALQ/USP. Bolsista da FAPESP. E-mails: prcursi@esalq.usp.br; tcolivei@esalq.usp.br

(4) Professor do Departamento de Solos e Nutrição de Plantas, ESALQ/USP. E-mail: mcooper@esalq.usp.br

(5) Professor Titular do Departamento de Ciências Biológicas, ESALQ/USP. E-mail: rrr@esalq.usp.br
} 
e pela pluviosidade. Em superfície, ocorre uma oscilação da umidade do solo intimamente ligada a eventos chuvosos. Em subsuperfície, este efeito é menos intenso, sendo deslocado no tempo. A disponibilidade de água em toda a toposseqüência é limitada na estação seca e também em parte da estação úmida, o que deve definir as características florísticas da formação florestal da parcela e determinar a distribuição espacial do mosaico vegetacional.

Termos de indexação: Cerrado, Latossolo, vertente, umidade do solo, retenção de água.

\title{
SUMMARY: SOIL WATER DYNAMICS IN A TOPOSEQUENCE UNDER SAVANNA WOODLAND (CERRADÃO) IN ASSIS, SP, BRAZIL
}

\begin{abstract}
The aim of this study was to characterize the morphological, physical and hydraulic soil properties in a toposequence under native plant cover in a permanent observation plot of $320 \times 320$ m installed in the Assis Ecological Station, São Paulo State, Brazil. The plot is covered by a remnant Savanna Woodland (Cerradão) vegetation of the southern border zone of the great Cerrado domain. The bi-dimensional geometry (horizontal and vertical) of the soil horizons in a toposequence provided details on the soil morphology. The soil water dynamics in the native plants environment was studied through determination of the soil-water retention curves as well as soil particle-size distribution, and saturated soil hydraulic conductivity using the Guelph permeameter. Soil moisture was measured in situ using a WCR sensor. Soil moisture and rainfall distribution were monitored from November 2003 to November 2004. The soils were classified, from the summit down to the footslope, as Rhodic Haplustox, Typic Haplustox and Epiaquic Haplustult. The high clay content in the subsurface horizon of the Epiaquic Haplustult, when compared to the Oxisols with greater sand content, determines less drainage, greater water retention and lower hydraulic conductivity. The soil moisture in this layer never attained the saturation during the study period. Soil water dynamics were influenced by relief conditions, as evidenced by the continuous lateral color transition, soil texture and structure, and by rainfall. At the soil surface, the soil moisture oscillation is closely related to the rain events. In the subsurface, this effect is less intense, and lagged in time. The water availability along the toposequence is limited in the dry season and in part of the wet season. The floristic characteristics of the forest formation and its mosaic distribution in the plot can be explained by the seasonal water availability.
\end{abstract}

Index terms: Cerrado, Oxisol, soil moisture, water retention.

\section{INTRODUÇÃO}

O Cerrado é a segunda maior formação florestal em área ocupada no Brasil, concentrada na região Centro-Oeste e abrangendo ainda parte das regiões Nordeste, Norte e Sudeste (Alho \& Martins, 1995). Esta formação florestal, que ainda cobre cerca de dois milhões de $\mathrm{km}^{2}$ da superfície do território nacional (Macedo, 1996), tem sido rapidamente destruída e substituída pela agricultura e silvicultura (Durigan et al., 1994). No Estado de São Paulo, por exemplo, a redução das áreas inicialmente cobertas por Cerrado foi de aproximadamente $87 \%$, no período de 1962 a 1992. Isto resultou em uma elevada fragmentação deste bioma, com $71,3 \%$ dos fragmentos remanescentes ocupando área menor que $0,2 \mathrm{~km}^{2}$ e apenas $0,46 \%$ ocupando mais de $4,0 \mathrm{~km}^{2}$ (Kronka et al., 1998).
A Savana Florestada (Cerradão), segundo a classificação de Veloso et al. (1991), é uma das subunidades fitogeográficas do Cerrado, de fisionomia florestal com árvores de até $15 \mathrm{~m}$ de altura, formando um dossel contínuo e ausência de gramíneas, ocorrendo em clima tropical eminentemente estacional. A ordem de solo predominante no Cerrado brasileiro é o Latossolo, que ocupa 48,8 \% da área total deste bioma (Macedo, 1996) e representa a zona de maior potencial de biodiversidade sob Cerrado (Brasil, 2002).

Ao estudar o solo em condições naturais, tornamse conhecidas as características e propriedades do solo e a dinâmica da água em que a vegetação original se desenvolve. O uso desse conhecimento é importante para o planejamento da restauração de áreas degradadas (Rodrigues \& Gandolfi, 1998), a partir da seleção de espécies nativas adaptadas ao 
solo e às condições ambientais dos locais destinados à revegetação (Rosa et al., 1997), a fim de formar-se uma floresta a mais próxima possível da nativa (Kageyama \& Gandara, 2004) e restabelecer a biodiversidade regional por meio de corredores de vegetação entre os fragmentos remanescentes (Brasil, 2002). A execução destas práticas de conservação do solo e da água pode ainda trazer outros benefícios, tais como: restaurar o padrão mais próximo possível do original de um solo degradado ou redistribuído pelo uso agrícola (Phillips et al., 1999).

O clima, o material de origem, a forma da vertente, os processos geomorfológicos e a infiltração de água, atuando de maneira conjunta, são alguns dos elementos responsáveis pela formação de solos diferenciados em uma mesma vertente. Nas últimas décadas, o estudo pedológico da vertente por meio de toposseqüências de solos tem apontado para influência de outros fatores de formação no desenvolvimento das características e propriedades dos solos (Rocha \& Carvalho, 2003).

O solo é um corpo contínuo que não se apresenta sob a forma de perfil vertical. Os perfis verticais são somente um produto do trabalho intelectual dos pedólogos concebido para facilitar a sua análise e delimitação na paisagem (Boulaine, 1982). Os maiores erros em classificação e mapeamento de solos são decorrentes da definição de unidades de mapeamento a partir de um pequeno conjunto de perfis de uma mesma classe de solo, o que é feito de modo subjetivo, provocando incongruências entre o sistema de classificação e a variabilidade contínua natural dos solos (Triantafilis et al., 2001).

Bocquier (1973) definiu toposseqüência como uma seqüência de diversos tipos de solos distribuídos de maneira regular e sistemática na paisagem de acordo com a topografia sobre um mesmo material de origem. A partir do estudo realizado por Bocquier (1973), novos métodos foram desenvolvidos para estudar a sucessão de perfis alinhados do topo à base de uma encosta, permitindo não só identificar a distribuição dos horizontes de solo, mas também as relações entre eles (Castro et al., 2003). A técnica proposta por Boulet et al. (1982), denominada análise estrutural, considera a geometria lateral e vertical de cada horizonte do solo. Esta técnica tende a auxiliar, cada vez mais, no diagnóstico de problemas de degradação dos solos por erosão, na compreensão da relação entre pedogênese e evolução do relevo (Queiroz Neto, 2002) e na avaliação do comportamento e funcionamento hídrico do solo, para ampliar os conhecimentos sobre as relações solo-planta (Queiroz Neto, 1988).

Poucos estudos têm abordado as propriedades físico-hídricas do solo e a morfologia junto à análise estrutural dos solos, para determinar as transições dos atributos dos solos presentes na toposseqüência e caracterizar a dinâmica do meio físico no qual a vegetação local está inserida e pelo qual é diretamente influenciada. Como exemplos, destacam-se os trabalhos de Sabatier et al. (1997), em solo sob floresta nativa da região equatorial, e de Cunha et al. (1999), com enfoque na prevenção e controle da erosão em solo sob diversas culturas, na região sul do Brasil. No Cerrado, Gomes et al. (2004) realizaram um levantamento físico, químico e mineralógico do solo, mas não consideraram dados pluviométricos ou de umidade do solo. Portanto, a dinâmica da água no solo necessita ser incluída em estudos sobre as relações solo-planta por ser considerada um fator importante na definição do tipo de vegetação local (Ruggiero et al., 2002).

O objetivo deste estudo foi caracterizar o comportamento físico-hídrico do solo por um ano em sistema não perturbado pela ação antropogênica em uma toposseqüência localizada na Estação Ecológica de Assis, SP, Brasil, tendo em foco o papel da dinâmica da água no solo como possível fator definidor do tipo vegetacional existente, auxiliando, assim, na adequação das ações de conservação, manejo e restauração dessas formações florestais.

\section{MATERIAL E MÉTODOS}

O estudo foi realizado na Estação Ecológica de Assis, SP, Brasil, com área de 13,13 km², inserida na Floresta Estadual de Assis, com área total de $44,80 \mathrm{~km}^{2}$, localizada no município de Assis, SP, a $22^{\circ} 35^{\prime} \mathrm{S}$ e $50^{\circ} 22^{\prime} \mathrm{W}$, entre as altitudes de 520 e $590 \mathrm{~m}$, no Planalto Ocidental paulista (Durigan et al., 1999). O clima é classificado, segundo Köppen, como Cwa, mesotérmico, com precipitação anual acima de $1.400 \mathrm{~mm}$ e temperatura média anual de $20^{\circ} \mathrm{C}$ (Bologna et al., 2003).

Em uma parcela permanente previamente demarcada de $0,10 \mathrm{~km}^{2}$ com 256 subparcelas de $20 \times 20 \mathrm{~m}$, foi escolhida uma toposseqüência representativa dos solos predominantes, sob vegetação de Savana Florestada (Cerradão). A toposseqüência estava disposta de montante a jusante na linha de maior declive da vertente. Cinco trincheiras de $1,5 \mathrm{~m}$ de profundidade foram abertas ao longo da toposseqüência para caracterização de cada classe de solo encontrada, procedendo à descrição morfológica de acordo com Lemos \& Santos (2002). A distribuição geométrica dos horizontes na toposseqüência seguiu o método desenvolvido por Boulet et al. (1982). O detalhamento foi feito por meio de tradagens sucessivas entre as trincheiras, a montante, na média encosta, e a jusante, com interpolações entre esses pontos.

Amostras de solo deformadas foram coletadas, secas ao ar e peneiradas em malha de $2 \mathrm{~mm}$ (TFSA) para análises granulométricas, a partir do método do densímetro de Bouyoucos modificado, utilizando solução de Calgon (Kiehl, 1979; Camargo et al., 1986). 
As amostras deformadas foram coletadas em cada horizonte nas trincheiras e em cada $0,2 \mathrm{~m}$ de profundidade nas tradagens executadas na análise estrutural e na amostragem uniforme feita a cada $10 \mathrm{~m}$ de distância na toposseqüência. Foram coletadas, por horizonte, amostras indeformadas em cilindros de $0,1 \mathrm{dm}^{3}$, em triplicata, para determinar a densidade do solo e obter as curvas de retenção de água no solo em nove potenciais matriciais: $1,3,5$, 8 e $10 \mathrm{kPa}$, determinados sobre quartzo moído de granulação fina em panela conectada a uma coluna de tensão de água, e 33, 100, 500 e $1.500 \mathrm{kPa}$, sobre placa porosa em câmaras de pressão de Richards.

A medida in situ da dinâmica da água no solo foi obtida por meio de sensores de umidade do solo do modelo WCR (CS615, Campbell Scientific Inc.), ainda pouco utilizado sob condições de clima tropical, mas de eficiência comprovada em relação ao TDR convencional (Seyfried \& Murdock, 2001). Os sensores foram instalados em horizontes de solo nos cinco perfis descritos em campo, sendo conectados a um multiplexador. Os dados foram armazenados em um "data logger" (CR10X, Campbell Scientific Inc.) a cada 20 min. O sistema foi mantido em funcionamento por bateria carregada por painel solar. A coleta desses registros no campo foi feita a cada 20 dias, no período de novembro de 2003 a novembro de 2004 . Os dados de precipitação foram coletados em uma estação meteorológica automática instalada no local e correlacionados com os dados de umidade do solo.

A condutividade hidráulica saturada de campo (Kfs) foi obtida com o permeâmetro de Guelph modificado (Vieira, 1995/1998), utilizando a aproximação das equações simultâneas (Reynolds \& Elrick, 1986).

Os dados foram calibrados a partir da coleta de amostras deformadas nas profundidades de instalação dos sensores WCR. O procedimento para a confecção das curvas e equações de calibração do WCR consistiu em saturar TFSA em tubos de PVC e drenar em cinco períodos consecutivos de 15 minutos, um, dois, quatro e seis dias. Para cada período de drenagem, foram obtidos a umidade volumétrica do solo em laboratório e o período em milissegundos, medido em triplicata com o WCR. A equação de calibração foi obtida a partir do ajuste da curva construída a partir da umidade volumétrica e da média do período de saída do WCR para cada tempo de drenagem.

Desta forma, as equações de calibração obtidas para os solos estudados são:

Para o horizonte Btg2 do Gleissolo (T5):

$$
\mathrm{Uv}=-1,0866+(1,9242 * \tau)-\left(0,6262 * \tau^{2}\right)
$$

Para todos os demais horizontes:

$$
\mathrm{Uv}=0,8298-(0,6135 / \tau)
$$

em que $\mathrm{Uv}=$ umidade volumétrica $\left(\mathrm{m}^{3} \mathrm{~m}^{-3}\right)$; e $\tau=$ período em milissegundos medido em campo pelo sensor WCR.
Foi utilizada análise de regressão para o ajuste das curvas de retenção de água no solo (Van Genuchten, 1980) e equações das curvas de calibração.

\section{RESULTADOS E DISCUSSÃO}

$\mathrm{Na}$ toposseqüência, os solos foram classificados como Latossolo Vermelho distrófico típico (LVd) em T1 e T2; Latossolo Vermelho-Amarelo distrófico típico (LVAd) em T3; Latossolo Amarelo distrófico típico (LAd) em T4; e Gleissolo Háplico Tb distrófico argissólico (GXbd) em T5 (Embrapa, 1999), conforme o mapa pedológico ultradetalhado da parcela permanente e descrição morfológica simplificada (Quadro 1).

A declividade média da encosta de $0,06 \mathrm{~m} \mathrm{~m}^{-1}$ (6\%) (Figura 1) caracteriza um relevo suave ondulado (Lemos \& Santos, 2002) e está incluída na faixa de declividade típica para solos de Cerrado (Resck, 2002). Os solos da região em estudo desenvolveram-se a partir de arenito do grupo Bauru, formação Adamantina, com predomínio de Latossolos em situação de relevo suave ondulado a plano (Lepsch et al., 1977; Moniz, 1996; Bologna et al., 2003). A distribuição dos solos na toposseqüência estudada (Figura 1) é bastante homogênea, predominando solos profundos e bem drenados do terço superior ao inferior da vertente (T1 a T4), com exceção do sopé onde existe um perfil com drenagem imperfeita em profundidade (T5).

As classes de textura (Quadro 1) estão de acordo com o triângulo americano modificado (Lemos \& Santos, 2002), a partir do resultado da análise granulométrica (Figura 2). A textura dos Latossolos (T1 a T4) é uniforme, com pequeno incremento de argila do horizonte $\mathrm{A}$ aos horizontes subsuperficiais, em geral de textura franco-arenosa em todo o perfil, com exceção de T1 e T4 cujo horizonte A é mais arenoso (areia franca). No Gleissolo (T5), os horizontes superficiais (A a E) pertencem à classe de textura areia franca, enquanto, nos horizontes glei, a classe textural varia de franco-arenosa (Eg e Btg1) a franco-argilo-arenosa em Btg2. O caráter argissólico neste perfil é devido ao gradiente textural que ocorre entre os horizontes superficiais (A a E) e aos horizontes diagnósticos (Btg1 e Btg2) (Quadro 1). Em toda a toposseqüência, a estrutura mantém-se grumosa ou granular no horizonte A, mesmo com grau fraco e textura arenosa, dada a presença de matéria orgânica e raízes. Nos horizontes subsuperficiais, o grau de estrutura torna-se forte, variando de granular muito pequena, em $\mathrm{T} 1$ e $\mathrm{T} 4$, a blocos subangulares médios e pequenos, em T5.

Salomão \& Queiroz Neto (1996) encontraram na região de Bauru, no Planalto Ocidental paulista, um sistema de solos semelhante à toposseqüência em estudo, com transição muito homogênea, tanto vertical 
Quadro 1. Descrição morfológica simplificada dos perfis de solo estudados

\begin{tabular}{|c|c|c|c|c|}
\hline Horizonte & Profundidade & $\begin{array}{c}\text { Cor } \\
\text { úmida(1) }^{(1)}\end{array}$ & Estrutura & Texture \\
\hline & $\mathrm{m}$ & Munsell & & \\
\hline \multicolumn{5}{|c|}{ Perfil T1 - Latossolo Vermelho distrófico típico (LVd) } \\
\hline $\mathrm{A}$ & $0-0,25$ & $5 Y R 4 / 4$ & Fraca pequena e média grumosa & Areia franca \\
\hline $\mathrm{AB}$ & $0,25-0,56$ & $5 Y R 4 / 4$ & Fraca pequena a média blocos subangulares & Franco-arenosa \\
\hline Bw1 & $0,56-0,94$ & $2,5 \mathrm{YR} 4 / 6$ & Forte muito pequena granular & Franco-arenosa \\
\hline Bw2 & $0,94-1,42+$ & $2,5 \mathrm{YR} 4 / 6$ & Forte muito pequena granular & Franco-arenosa \\
\hline
\end{tabular}

Perfil T2 - Latossolo Vermelho distrófico típico (LVd)

$\begin{array}{lllll}\text { A } & 0-0,14 & 5 Y R 4 / 6 & \text { Fraca pequena e média grumosa } & \text { Franco-arenosa } \\ \text { AB } & 0,14-0,32 & 5 Y R 4 / 4 & \text { Fraca pequena a média blocos subangulares } & \text { Franco-arenosa } \\ \text { Bw1 } & 0,32-0,86 & 2,5 Y R 4 / 6 & \text { Forte muito pequena granular } & \text { Franco-arenosa } \\ \text { Bw2 } & 0,86-1,42+ & 2,5 Y R 4 / 6 & \text { Forte muito pequena granular } & \text { Franco-arenosa }\end{array}$

Perfil T3 - Latossolo Vermelho-Amarelo distrófico típico (LVAd)

$\begin{array}{lllll}\mathrm{A} & 0-0,20 & 5 \mathrm{YR} 4 / 4 & \text { Fraca pequena grumosa } & \text { Franco-arenosa } \\ \mathrm{AB} & 0,20-0,60 & 5 \mathrm{YR} 4 / 4 & \text { Fraca pequena a média blocos subangulares } & \text { Franco-arenosa } \\ \mathrm{BA} & 0,60-0,87 & 5 Y R 4 / 6 & \begin{array}{l}\text { Fraca pequena a média blocos subangulares e } \\ \text { forte muito pequena granular }\end{array} & \text { Franco-arenosa } \\ \mathrm{Bw} & 0,87-1,45+ & 5 Y R 4,5 / 6 & \text { Forte muito pequena granular } & \text { Franco-arenosa }\end{array}$

Perfil T4 - Latossolo Amarelo distrófico típico (LAd)

$\begin{array}{lllll}\text { A } & 0-0,20 & 7,5 \text { YR 5/4 } & \text { Fraca pequena e média granular } & \text { Areia franca } \\ \text { AB } & 0,20-0,66 & 7,5 \text { YR 5/4 } & \text { Fraca pequena e média blocos subangulares } & \text { Franco-arenosa } \\ \text { BA } & 0,66-0,93 & 7,5 \text { YR 4/6 } & \begin{array}{l}\text { Fraca pequena e média blocos subangulares e } \\ \text { forte muito pequena granular }\end{array} & \text { Franco-arenosa } \\ \text { Bw } & 0,93-1,50+ & 7,5 Y R 5 / 6 & \text { Forte muito pequena granular } & \text { Franco-arenosa }\end{array}$

Perfil T5 - Gleissolo Háplico Tb distrófico argissólico (GXbd)

\begin{tabular}{|c|c|c|c|c|}
\hline A & $0-0,20$ & 10YR $5 / 2$ & Fraca pequena grumosa & Areia franca \\
\hline $\mathrm{AE}$ & $0,20-0,37$ & 10YR $5 / 3$ & Fraca pequena e média blocos subangulares & Areia franca \\
\hline $\mathrm{E}$ & $0,37-0,80$ & $10 \mathrm{YR} 5 / 3$ & Fraca média a grande blocos subangulares & Areia franca \\
\hline $\mathrm{Eg}$ & $0,80-1,08$ & $\begin{array}{l}10 \mathrm{YR} 5 / 3 \\
\text { M: } 7,5 \mathrm{YR} 5 / 8 \\
7,5 \mathrm{YR} 6 / 6 \\
\text { e } 5 \mathrm{YR} 5 / 8\end{array}$ & Fraca média blocos subangulares & Franco-arenosa \\
\hline
\end{tabular}

\begin{tabular}{|c|c|c|c|c|}
\hline Btg 1 & $1,08-1,38$ & $\begin{array}{c}\text { 10YR 6/2 } \\
\text { M: 7,5YR 5/8, } \\
\text { 7,5YR 6/6 } \\
\text { e 5YR 5/8 }\end{array}$ & $\begin{array}{l}\text { Moderada pequena a média blocos } \\
\text { subangulares }\end{array}$ & Franco-arenosa \\
\hline Btg2 & $1,38-1,60+$ & $\begin{array}{c}\text { 10YR 7/1 } \\
\text { M: 10YR 6/6, } \\
\text { 7,5YR 6/6 } \\
\text { e } 2,5 \text { YR 4/6 }\end{array}$ & $\begin{array}{l}\text { Moderada a forte pequena e média blocos } \\
\text { subangulares }\end{array}$ & Franco-argilo-arenosa \\
\hline
\end{tabular}

(1) M: mosqueados; N: nódulos. 


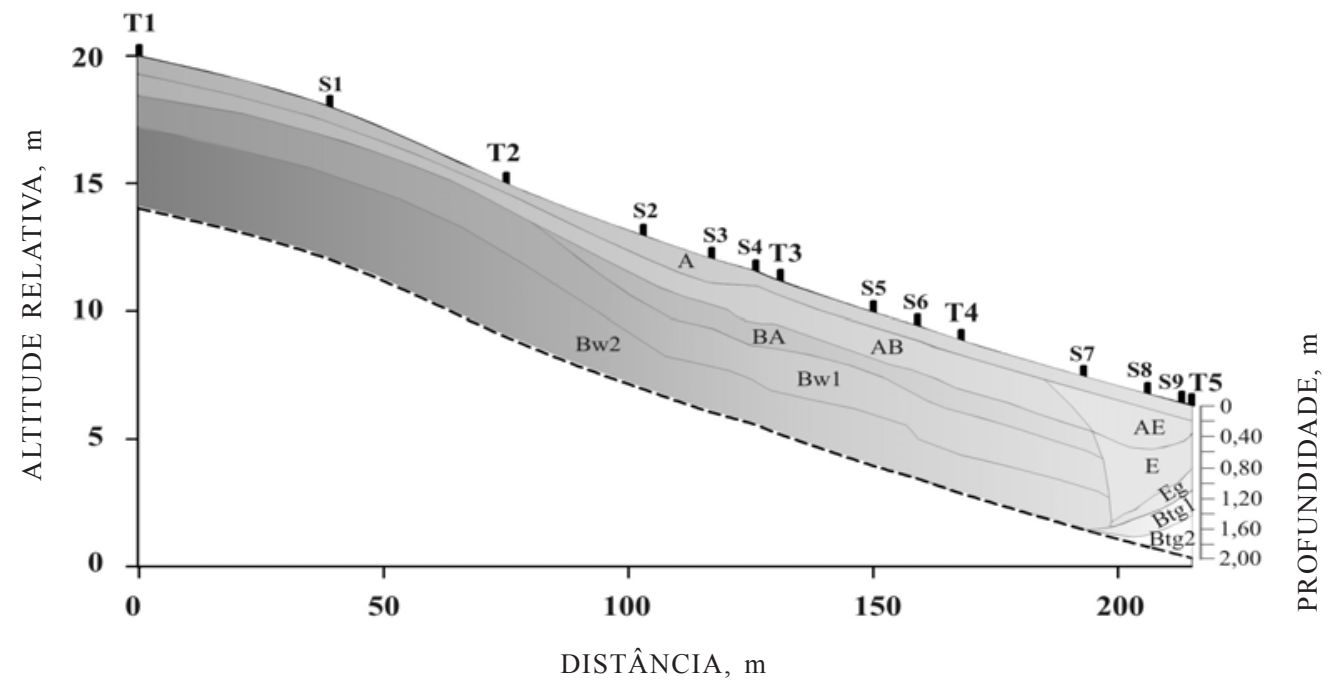

Figura 1. Análise estrutural da toposseqüência. $T=$ trincheira; $S=$ tradagem.

quanto lateralmente, de Latossolos franco-arenosos a montante para Gleissolo arenoso no sopé da vertente. Este sistema ocorre em colinas amplas a intermediárias de relevo suave ondulado com declividades inferiores a $0,06 \mathrm{~m} \mathrm{~m}^{-1}$, ocupando cerca de $50 \%$ da região. Esta seqüência de solos, cujos horizontes recobrem continuamente as vertentes, transformando-se nos sopés em solos hidromórficos, também foi relatada por Queiroz Neto (2002). Na região em estudo, a ocorrência de Latossolos de textura média e arenosa/média nos topos amplos e aplainados (relevo plano a suave ondulado) deve-se à presença exclusiva de arenitos do grupo Bauru (Bertolani et al., 2003). Santos et al. (1998) ainda observaram a ocorrência de Latossolo Vermelho a montante em transição progressiva a Latossolo Amarelo a jusante, assim como os Latossolos (T1 a T4) da toposseqüência estudada (Figura 1). A textura franco-arenosa e a estrutura em microagregados muito porosa em profundidade, sob um horizonte superficial ligeiramente mais arenoso (Figura 2), foram também observadas por Salomão \& Queiroz Neto (1996) e Santos et al. (1998), em semelhança à toposseqüência em estudo.

À medida que aumenta a declividade, de 0,06 a $0,12 \mathrm{~m} \mathrm{~m}^{-1}$, ocorre outro sistema de solos, surgindo solos com B textural e forte gradiente textural entre os Latossolos no topo das colinas e os Gleissolos no sopé (Salomão \& Queiroz Neto, 1996). Portanto, o caráter argissólico do Gleissolo (T5) da toposseqüência em estudo pode representar uma transição entre os dois sistemas de solo apresentados, visto que a declividade média de $0,06 \mathrm{~m} \mathrm{~m}^{-1}$ está na faixa limítrofe entre esses sistemas.

A estrutura granular muito pequena e forte do horizonte $\mathrm{Bw}$ (T1 a T4) comporta-se como a estrutura grumosa de superfície (horizonte A), como evidenciada pela condutividade hidráulica maior do que na estrutura em blocos subangulares de grau fraco no horizonte $\mathrm{AB}$ (T1 a T4) (Quadros 1 e 2). Os valores de condutividade hidráulica saturada de campo (Kfs) (Quadro 2) na ordem de $10^{-5} \mathrm{~m} \mathrm{~s}^{-1}$ correspondem a meios porosos de alta permeabilidade, enquanto, na ordem de $10^{-6} \mathrm{~m} \mathrm{~s}^{-1}$, a permeabilidade é intermediária (Reynolds \& Elrick, 1986). Em geral, Latossolos de textura média sob Cerrado, como os perfis T1 a T4, apresentam condutividade hidráulica saturada constante e elevada (Salomão \& Queiroz Neto, 1996) e alta permeabilidade graças à elevada proporção de areia (Costa et al., 2002). A condutividade hidráulica saturada do horizonte $\mathrm{Bw}$ dos Latossolos da toposseqüência em estudo, representados pelo perfil T1 (Latossolo Vermelho) (Quadro 2), está de acordo com a faixa de condutividade obtida por Santos et al. (1998) para horizonte Bw de Latossolos de textura média formados sobre arenito do Grupo Bauru.

Quadro 2. Condutividade hidráulica saturada de campo (Kfs) nos extremos da toposseqüência

\begin{tabular}{|c|c|c|}
\hline Horizonte & Profundidade de amostragem & $\mathbf{K f s}$ \\
\hline & $\mathrm{m}$ & $\mathrm{m} \mathrm{s}^{-1}$ \\
\hline \multicolumn{3}{|c|}{ Perfil T1 - Latossolo Vermelho (LVd) } \\
\hline A & 0,10 & $5,510^{-5}$ \\
\hline $\mathrm{AB}$ & 0,50 & $1,610^{-5}$ \\
\hline $\mathrm{Bw}$ & 1,00 & $5,710^{-5}$ \\
\hline \multicolumn{3}{|c|}{ Perfil T5 - Gleissolo Háplico (GXbd) } \\
\hline $\mathrm{A}$ & 0,10 & $6,910^{-5}$ \\
\hline $\mathrm{E}$ & 0,50 & $3,010^{-5}$ \\
\hline Btg & 1,50 & $1,810^{-6}$ \\
\hline
\end{tabular}


Entretanto, no horizonte Btg (T5), a permeabilidade é intermediária (baixo valor de Kfs) (Quadro 2) e pode ser decorrente da estrutura de grau forte (Quadro 1) e do incremento no teor de argila (Figura 2). Pode-se ainda observar que a estrutura em blocos subangulares provoca uma redução na condutividade hidráulica no solo, uma vez que, tanto em grau fraco (T1, AB e T5, E) como em grau forte (T5, Btg), o valor de $\mathrm{Kfs}$ foi menor.

No topo e no terço superior da vertente (T1 e T2), com inclinação mais suave, predominam condições de oxidação com cores de alto croma (Richardson \& Daniels, 1993), com matiz vermelho, 2,5YR na escala de Munsell (Quadro 1) no horizonte diagnóstico Bw, podendo caracterizar predomínio de hematita (óxido de $\mathrm{Fe}$ ). À medida que se direciona a jusante, outros compostos imóveis de $\mathrm{Fe}$ de baixa solubilidade começam a predominar em relação à hematita, tornando as cores cada vez mais amarelas, quando não mascaradas pela matéria orgânica. No perfil T3, ainda pode haver alto conteúdo de hematita, mas já com uma proporção maior de goethita, exibindo matiz 5YR (vermelho-amarelo). Em T4, deve haver o predomínio de goethita (oxidróxido de $\mathrm{Fe}$ ), com matiz 7,5YR (amarelo) graças à remoção de Fe ou, ainda, à substituição do Fe por Al (Schwertmann, 1993), encontrado em quantidade elevada em solos muito intemperizados.

No sopé da vertente (T5), ocorre processo de gleização (horizontes Eg, Btg1 e Btg2) causado pela saturação periódica de água no solo, estabelecendo um ambiente de oxirredução (Breemen \& Buurman,
1998). Em condições anaeróbias, as partículas de Fe(III) reduzem-se a Fe(II) e tornam-se solúveis, levando à mobilização do $\mathrm{Fe}$ (solúvel) e à conseqüente segregação de óxidos de $\mathrm{Fe}$ e formação de algumas zonas de depleção (claras) e outras de enriquecimento (avermelhadas) (Rabenhorst \& Parikh, 2000), denominadas mosqueados e nódulos ou concreções, como aqueles observados em T5 (Quadro 1). A matiz dominante $10 \mathrm{YR}$ (ou mais amarela), com valor $\geq 4 \mathrm{e}$ croma $\leq 2$, designa um horizonte glei (g) (Embrapa, 1999).

Os horizontes A e E, em T5, apresentam cores mais claras provavelmente em razão de quantidades insuficientes de agentes pigmentantes (como óxidos de $\mathrm{Fe}$ ), tornando a cor dominante nestes horizontes a dos próprios grãos minerais (Rabenhorst \& Parikh, 2000). Nos horizontes superficiais, o croma menor (Quadro 1), que representa cores mais escuras, é devido à influência da matéria orgânica e atividade biológica.

O comportamento físico-hídrico e a retenção de água nos solos (Figura 3) são influenciados tanto pela textura e estrutura dos solos quanto pela intensidade dos eventos pluviométricos (Figura 4).

A partir da curva de retenção de água nos solos (Figura 3), pode-se dividir a porosidade do solo entre macro e microporos pelo potencial matricial de $6 \mathrm{kPa}$ (Resck, 2002). Nos horizontes de solo mais arenosos da toposseqüência ( $\mathrm{A}, \mathrm{E}$ e $\mathrm{Bw}$ ), a macroporosidade é elevada e predomina a circulação hídrica vertical, assim como observado por Salomão \& Queiroz Neto (1996) e Cunha et al. (1999). Este comportamento é
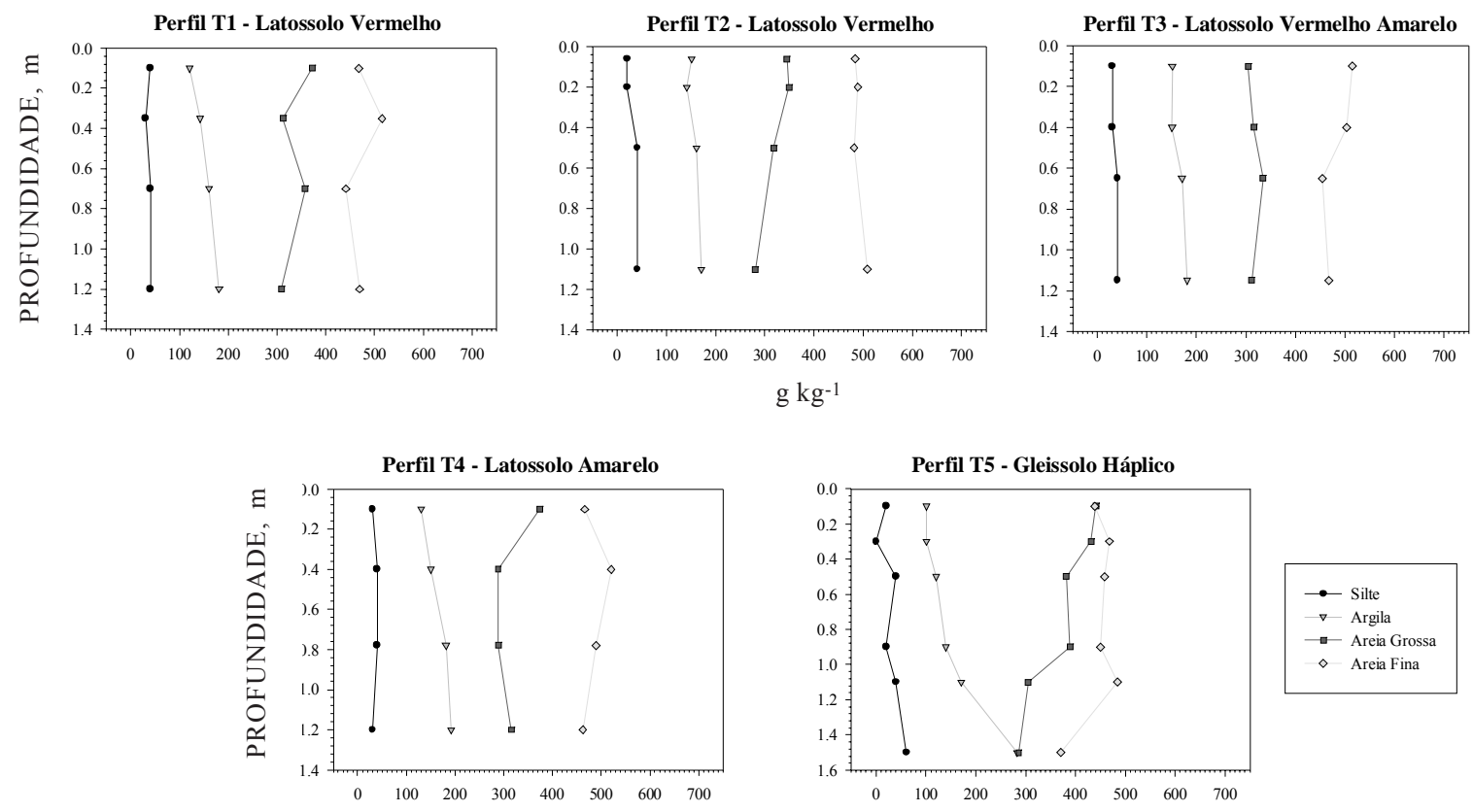

$\mathrm{g} \mathrm{kg}^{-1}$

Figura 2. Distribuição das frações silte $(0,002$ a $0,05 \mathrm{~mm})$, argila $(<0,002 \mathrm{~mm})$, areia grossa $(0,2$ a $2 \mathrm{~mm})$ e areia fina $(0,05$ a $0,2 \mathrm{~mm})$ dos cinco perfis descritos. 


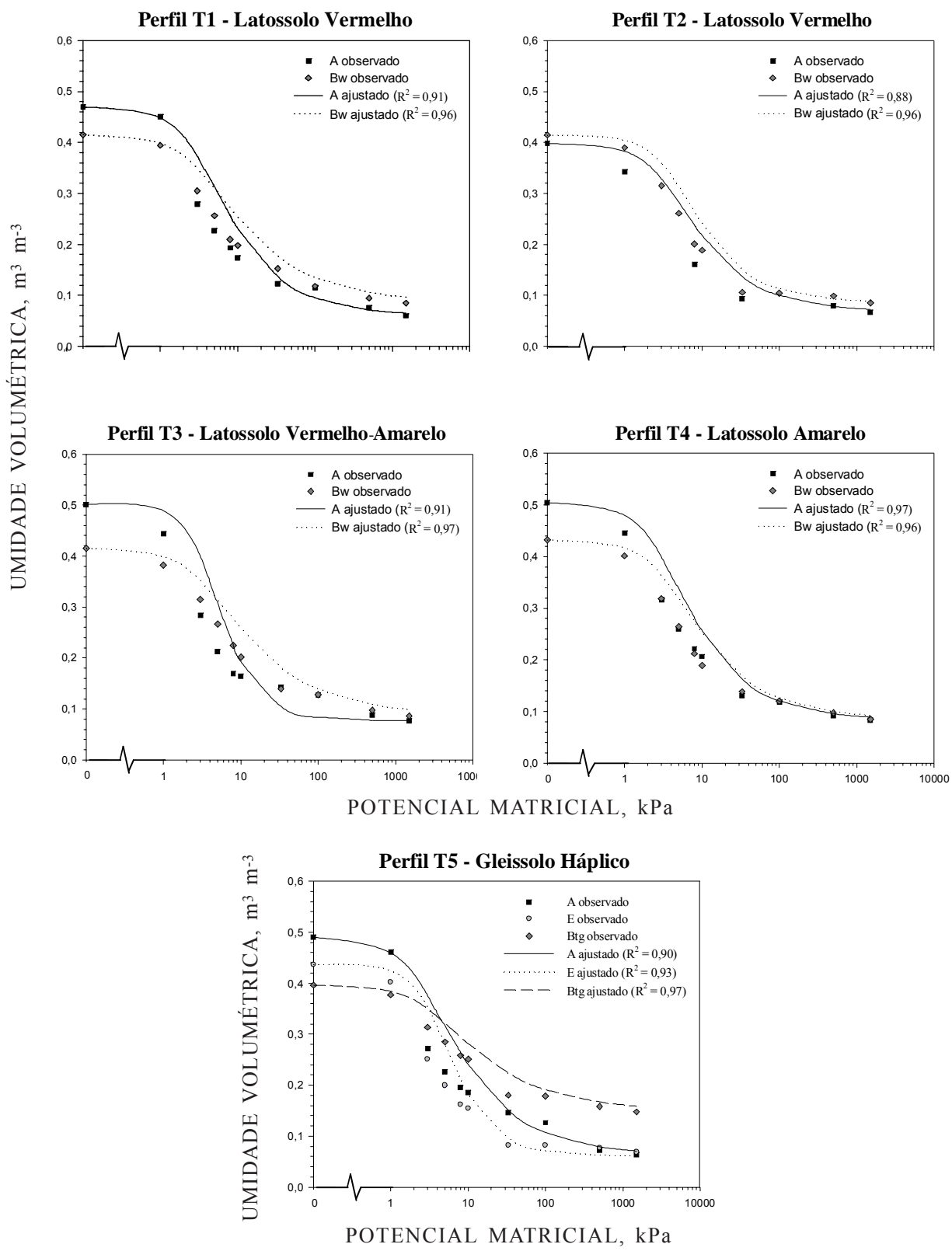

Figura 3. Curvas de retenção de água ajustadas a partir dos respectivos pontos amostrados em superfície e subsuperfície dos cinco perfis de solo estudados.

evidenciado pela acentuada inclinação da curva de retenção em relação ao eixo do potencial matricial (Figura 3) que representa uma condição de drenagem excessiva nos horizontes analisados. Todavia, o horizonte Btg no Gleissolo (T5), mais argiloso, dispõe de maior retenção hídrica e maior proporção de microporos em relação a macroporos do que os horizontes adjacentes, evidenciadas pela curva de retenção menos inclinada em relação ao eixo do potencial matricial (Figura 3). Isto se deve, principalmente, ao aumento no teor de argila e às mudanças de estrutura em relação aos horizontes adjacentes.

Em superfície, a oscilação de umidade no solo é muito freqüente e os picos de umidade seguem imediatamente os eventos pluviométricos, por ser, nesta camada, maior a concentração de raízes, com absorção mais intensa de água da chuva, além do componente gravitacional que drena rapidamente esta água no sentido vertical sem qualquer impedimento. Outros fatores são a classe textural no limite entre areia franca e franco-arenosa (Quadro 1), considerando os baixos teores de argila e silte (Figura 2) e a estrutura grumosa ou granular (Quadro 1), tornando a infiltração de água mais rápida nessa camada, o que é evidenciado pela elevada condutividade hidráulica no horizonte A (Quadro 2). Portanto, a água da chuva não se concentra em superfície, de modo que o valor mínimo de umidade volumétrica 
(aproximadamente $0,1 \mathrm{~m}^{3} \mathrm{~m}^{-3}$ ) (Figura 4) corresponde a tensões elevadas, mas que não alcançam o ponto de murcha permanente $(-1.500 \mathrm{kPa})$ (Figura 3) em nenhum momento do ano.
Nos Latossolos (T1 a T4), em subsuperfície, o efeito das chuvas na umidade do solo é deslocado no tempo, ou seja, após eventos pluviométricos de volume menor que $4 \mathrm{~mm}$, a umidade do solo continua decrescendo, e

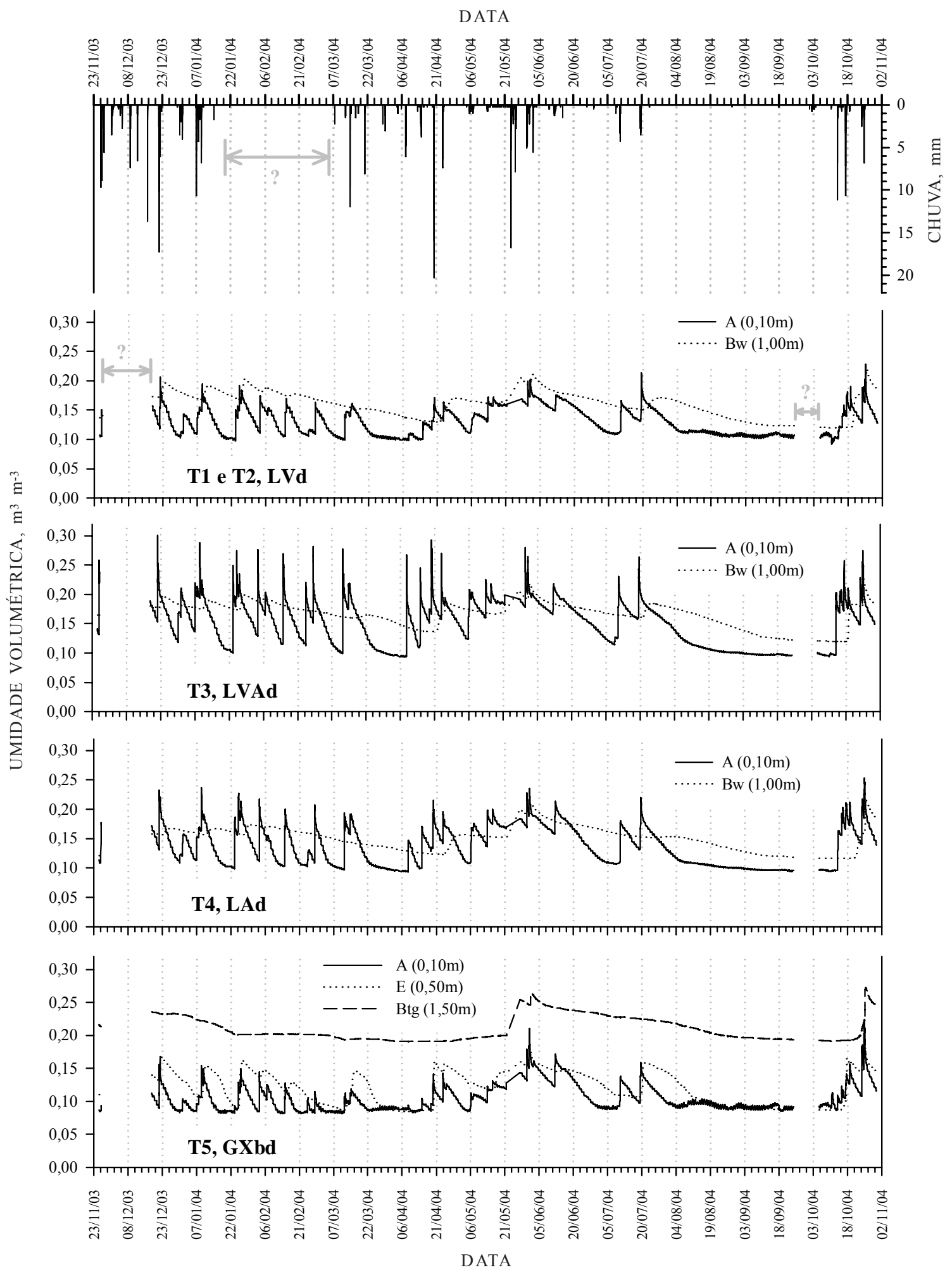

Figura 4. Efeito das chuvas sobre o funcionamento hídrico dos solos em superfície e subsuperfície. $O$ "?" indica ausência de dados. Nas legendas, estão indicados os horizontes, nos quais foram instalados os sensores WCR na profundidade indicada entre parênteses. 
de 4 a $10 \mathrm{~mm}$, podem ocorrer picos de elevação pequenos e rápidos (Figura 4). Somente quando o volume medido de chuva é maior que $10 \mathrm{~mm}$, a umidade dos solos, em toda a toposseqüência, é capaz de aumentar e atingir a faixa de capacidade de campo entre -10 e $-33 \mathrm{kPa}$ (Figura 3). Em geral, os Latossolos de textura média, muito encontrados sob Cerrado, apresentam baixa disponibilidade de água, principalmente pela elevada proporção de areia (Costa et al., 2002). Os valores mínimos de umidade do solo foram atingidos tanto no mês de abril (época de chuvas) quanto nos meses de setembro a outubro (época seca) (Figura 4) e, assim, a disponibilidade de água não é constante durante o ano, mesmo em alguns períodos da estação chuvosa.

A estrutura granular muito pequena e forte no $\mathrm{Bw}$ (T1 a T4) apresenta condutividade hidráulica tão alta quanto a estrutura grumosa ou granular de superfície (Quadro 2), evidenciada pela redução na umidade no solo do horizonte $\mathrm{Bw}$ acompanhando o horizonte $\mathrm{A}$ (Figura 4). Esta redução, porém, não é tão imediata como no horizonte $\mathrm{A}$, pois o pequeno incremento de argila em relação à superfície (Figura 2) já é suficiente para que a água fique mais retida a tensões maiores (Figura 3), graças à maior adesão da água às partículas coloidais. No horizonte Btg (T5), esta adesão (mais expressiva no Btg2) é ainda maior, em decorrência do alto teor de argila (Figura 2), que determina maior retenção de água (Figura 3), e de um valor maior de umidade no solo em relação aos outros horizontes (Figura 4), que também determina menor condutividade hidráulica.

No ano monitorado, não foi observada saturação por água no horizonte Btg2 (T5), indicando que as condições de hidromorfia provavelmente ocorreram em um período pretérito (Richardson \& Daniels, 1993). O tempo necessário para se formar um horizonte glei bem desenvolvido varia, provavelmente, de anos a décadas (Breemen \& Buurman, 1998). Deste modo, não se pode afirmar que a flutuação do lençol freático tenha atingido este nível de profundidade no solo recentemente, o que torna a altura do lençol freático um elemento mais explicativo (teórico) do que indicativo de redução (Campos et al., 2003). O grau de hidromorfismo baixo pode explicar o fato de que, neste solo, não ocorreu uma seletividade de espécies de plantas, em que ainda predominam a fisionomia de Savana Florestada (Cerradão) e a ausência de formações ciliares (Jacomine, 2004).

Em T3 (horizonte A), os picos de umidade ultrapassaram o limite de umidade máximo alcançado no horizonte glei (Btg) do perfil T5, mas, repentinamente, voltaram a níveis mais baixos de umidade do solo. Este comportamento pode ser explicado pela curva de retenção mais acentuada (Figura 3), ou seja, com inclinação maior da curva em relação ao eixo do potencial matricial, representada por uma queda abrupta na umidade do solo, à medida que se aumenta a pressão aplicada à amostra, evidenciando rápida drenagem.
Como em toda a toposseqüência é atingido o mesmo patamar mínimo de umidade (por exemplo, em superfície, aproximadamente $0,10 \mathrm{~m}^{3} \mathrm{~m}^{-3}$ ) ao mesmo tempo, não pode haver fluxo lateral nesta vertente, embora isto possa ser observado em outros tipos de solo e, principalmente, em declividades maiores (Moniz, 1996). Os valores ainda menores em T5 (Figura 4), próximos a $0,08 \mathrm{~m}^{3} \mathrm{~m}^{-3}$ nos horizontes A e E, devem ter influência principalmente da distribuição do tamanho de partículas no solo (Figura 2), mais grosseiras (arenosa) do que em T1 a T4.

Em todos os horizontes dos solos da toposseqüência, a disponibilidade de água para as plantas torna-se baixa, quando são atingidos os valores mínimos de umidade (Figura 4) que se aproximam do ponto de murcha permanente $(-1.500 \mathrm{kPa})$ (Figura 3$)$. A baixa disponibilidade de água no solo ocorre por um período relativamente extenso e contínuo na época seca e durante a época chuvosa, mas de maneira descontínua (Figura 4), principalmente no horizonte superficial que abriga geralmente a maior concentração de raízes das plantas. Portanto, este comportamento exige que as espécies de plantas apresentem algum tipo de adaptação para essa condição de déficit hídrico, tal como a presença de raízes profundas em muitas espécies de árvores do Cerrado (Alho \& Martins, 1995), considerando que os solos sob Cerrado, em condições originais, apresentam propriedades físicas que não limitam o desenvolvimento das raízes (Costa et al., 2002).

Novos estudos de correlação específicos às diversas classes de solo e respectivas formações florestais são recomendados (Jacomine, 2004). Esta carência em conhecimentos sobre as relações solo-vegetação será suprida, em boa parte, com a interação entre trabalhos de diversas áreas do conhecimento, incluindo a dinâmica de água no solo, gerando uma base de dados capaz de promover a compreensão dos processos geradores e mantenedores da biodiversidade em um dos principais biomas do Estado de São Paulo, Brasil.

\section{CONCLUSÕES}

1. A caracterização morfológica da toposseqüência evidenciou o domínio de solos profundos e bem drenados no terço superior e no médio da vertente, enquanto, no terço inferior, os solos apresentam drenagem impedida em profundidade.

2. O estudo em toposseqüências ou dos solos de acordo com o relevo é eficaz na compreensão das condições de oxidação e drenagem na vertente e das relações solo-planta.

3. O comportamento físico-hídrico dos solos estudados mostrou uma disponibilidade de água deficiente, exigindo que a vegetação dominante de Savana Florestada (Cerradão) mostre algum tipo de adaptação para suprir as necessidades hídricas durante todo o ano. 


\section{AGRADECIMENTOS}

Este trabalho foi apoiado/financiado pela Fundação de Amparo à Pesquisa do estado de São Paulo (FAPESP) no âmbito do Programa BIOTA/FAPESP O Instituto Virtual da Biodiversidade. Os autores agradecem também a André Oppitz Ketzer, Rodrigo Chiara Olsen, Raul Shiso Toma, Dorival Grisotto e Valter Novais, no auxílio ao trabalho de campo.

\section{LITERATURA CITADA}

ALHO, C.J.R. \& MARTINS, E.S., eds. De grão em grão, o cerrado perde espaço. (Cerrado - impactos do processo de ocupação). Brasília, WWF, Sociedade de Pesquisas Ecológicas do Cerrado (PRÓ-CER), 1995. (Documento para Discussão)

BERTOLANI, F.C.; OLIVEIRA, J.B. \& MENK, J.R.F. Variações morfopedológicas em áreas transicionais de arenito do grupo Bauru para basalto da formação Serra Geral, no Estado de São Paulo, Brasil. In: CONGRESSO BRASILEIRO DE CIÊNCIA DO SOLO, 29., Ribeirão Preto, 2003. Anais. Viçosa, MG, Sociedade Brasileira de Ciência do Solo, Botucatu/Ilha Solteira/Jaboticabal, Universidade Estadual Paulista "Júlio de Mesquita Filho", 2003. CDROM.

BOCQUIER, G. Génèse et évolution de deux toposéquences de sols tropicaux du Tchad: interprétation byogéodinamique. Paris, ORSTOM, 1973. 350p. (Mémoires ORSTOM, 62)

BOLOGNA, I.A.; PRADO, H.; MENK, J.R.F.; JOAQUIM, A.C. \& LEPSCH, I.F. Levantamento pedológico semidetalhado do Estado de São Paulo: Quadrícula de Assis. II. Memorial descritivo. Campinas, Instituto Agronômico, 2003. 54p. (Boletim Científico, Série Pesquisa APTA, 8)

BOULAINE, J. Remarques sur quelques notions élémentaires de la pédologie. 1. Pédon, Profil et Sol. 2. Les Horizons. 3. La variabilité latérale des sols. Cah. ORSTOM, Sér. Pédol., 19:19-41, 1982.

BOULET, R.; CHAUVEL, A.; HUMBEL, F.X. \& LUCAS, Y. Analyse structurale et cartographie en pédologie: I - Prise en compte de l'organisation bidimensionelle de la couverture pédologique: les études de toposéquences et leurs principaux apports à la connaissance dês sols. Cah. ORSTOM, Sér. Pédol., 19:309-321, 1982

BRASIL. Ministério do Meio Ambiente. Biodiversidade brasileira: avaliação e identificação de áreas e ações prioritárias para conservação, utilização sustentável e repartição dos benefícios da biodiversidade nos biomas brasileiros. Brasília, Projeto de conservação e de utilização sustentável da diversidade biológica brasileira, PROBIO, 2002. 404p. (Série Biodiversidade, 5)

BREEMEN, N. van \& BUURMAN, P. Soil formation. Dordrecht, Kluwer Academic Publishers, 1998. 376p.

CAMARGO, O.A.; MONIZ, A.C.; JORGE, J.A. \& VALADARES, J.M.A.S. Métodos de análise química, mineralógica e física de solos do Instituto Agronômico de Campinas. Campinas, Instituto Agronômico, 1986. 94p. (Boletim Técnico, 106)
CAMPOS, C.E.B.; LANI, J.L.; RESENDE, M. \& REZENDE, S.B. Indicadores de campo para solos hidromórficos na região de Viçosa (MG). R. Bras. Ci. Solo, 27:1057-1066, 2003.

CASTRO, S.S.; COOPER, M.; SANTOS, M.C. \& VIDAL TORRADO, P. Micromorfologia do solo: Bases e aplicações. In: CURI, N.; MARQUES, J.J.; GUILHERME, L.R.G.; LIMA, J.M.; LOPES, A.S. \& ALVAREZ V., V.H., eds. Tópicos em ciência do solo. Viçosa, MG, Sociedade Brasileira de Ciência do Solo, 2003. v.3. p.107-164.

COSTA, L.M.; NACIF, P.G.S.; COSTA, O.V. \& OLSZEVSKI, N. Manejo dos solos da região dos Cerrados. In: ARAÚJO, Q.R., org. 500 anos de uso do solo no Brasil. Ilhéus, Editus, 2002. p.201-218.

CUNHA, J.E.; CASTRO, S.S. \& SALOMÃO, F.X.T. Comportamento erosivo de um sistema pedológico de Umuarama, noroeste do Estado do Paraná. R. Bras. Ci. Solo, 23:943-951, 1999

DURIGAN, G.; LEITÃO FILHO, H.F. \& RODRIGUES, R.R. Phytosociology and structure of a frequently burnt cerrado vegetation in SE - Brazil. Flora, 189:153-160, 1994.

DURIGAN, G.; BACIC, M.C.; FRANCO, G.A.D.C. \& SIQUEIRA, M.F. Inventário florístico do cerrado na estação ecológica de Assis, SP. Hoehnea, 26:149-172, 1999.

EMPRESA BRASILEIRA DE PESQUISA AGROPECUÁRIA EMBRAPA. Centro Nacional de Pesquisa de Solos. Sistema Brasileiro de classificação de solos. Brasília, Embrapa Serviço de Produção de Informação; Rio de Janeiro, Embrapa Solos, 1999. 412p.

GOMES, J.B.V.; CURI, N.; MOTTA, P.E.F.; KER, J.C.; MARQUES, J.J.G.S.M. \& SCHULZE, D.G. Análise de componentes principais de atributos físicos, químicos e mineralógicos de solos do bioma Cerrado. R. Bras. Ci. Solo, 28:137-153, 2004

JACOMINE, P.K.T. Solos sob matas ciliares. In: RODRIGUES, R.R. \& LEITÃO FILHO, H.F., eds. Matas ciliares: Conservação e recuperação. 2.ed. São Paulo, Universidade de São Paulo, FAPESP, 2004. p.27-31.

KAGEYAMA, P. \& GANDARA, F.B. Recuperação de áreas ciliares. In: RODRIGUES, R.R. \& LEITÃO FILHO, H.F., eds. Matas ciliares: Conservação e recuperação. 2.ed. São Paulo, Universidade de São Paulo, FAPESP, 2004. p.249269.

KIEHL, E.J. Manual de edafologia. Relações solo-planta. São Paulo, Agronômica Ceres, 1979. 264p.

KRONKA, F.L.N.; NALON, M.A.; MATSUKUMA, C.K.; PAVÃO, M.; GUILLAUMON, J.R.; CAVALLI, A.C.; GIANOTTI, E.; YWANE, M.S.S.I.; LIMA, L.M.P.R.; MONTES, J. DEL CALI, I.H. \& HAACK, P.G. Áreas de domínio do cerrado no Estado de São Paulo. São Paulo, Secretaria do Meio Ambiente, 1998. 84p.

LEMOS, R.C. \& SANTOS, R.D. Manual de descrição e coleta de solo no campo. 4.ed. Viçosa, MG, Sociedade Brasileira de Ciência do Solo, 2002. 83p.

LEPSCH, I.F.; BUOL, S.W. \& DANIELS, R.B. Soil-landscape relationships in the occidental plateau of São Paulo, Brazil: II. Soil morphology, genesis and classification. Soil Sci. Soc. Am. J., 41:109-115, 1977. 
MACEDO, J. Os solos da região dos cerrados. In: ALVAREZ V., V.H.; FONTES, L.E.F. \& FONTES, M.P.F., eds. O solo nos grandes domínios morfoclimáticos do Brasil e o desenvolvimento sustentado. Viçosa, MG, Sociedade Brasileira de Ciência do Solo, Universidade Federal de Viçosa, 1996. p.135-155.

MONIZ, A.C. Evolução de conceitos no estudo da gênese de solos. R. Bras. Ci. Solo, 20:349-362, 1996.

PHILLIPS, J.D.; GARES, P.A. \& SLATTERY, M.C. Agricultural soil redistribution and landscape complexity. Landscape Ecol., 14:197-211, 1999.

QUEIROZ NETO, J.P. Análise estrutural da cobertura pedológica no Brasil. In: MONIZ, A.C.; FURLANI, A.M.C.; FURLANI, P. \& FREITAS, S.S., coords. A responsabilidade social da ciência do solo. Campinas, Sociedade Brasileira de Ciência do Solo, 1988. p.415-429.

QUEIROZ NETO, J.P. Análise estrutural da cobertura pedológica: Uma experiência de ensino e pesquisa. R. Depto. Geografia USP, 15:77-90, 2002.

RABENHORST, M.C. \& PARIKH, S. Propensity of soils to develop redoximorphic color changes. Soil Sci. Soc. Am. J., 64:1904-1910, 2000.

RESCK, D.V.S. Perspectivas do uso e manejo dos solos no Cerrado. In: ARAÚJO, Q.R., org. 500 anos de uso do solo no Brasil. Ilhéus, Editus, 2002. p.218-237.

REYNOLDS, W.D. \& ELRICK, D.E. A method for simultaneous in situ measurement in the vadose zone of field saturated hydraulic conductivity, sorptivity and the conductivity-pressure head relationship. Ground Water Monit. Rev., 6:84-95, 1986.

RICHARDSON, J.J. \& DANIELS, R.B. Stratigraphic and hydraulic influences on soil color development. In: BIGHAM, J.M. \& CIOLKOSZ, E.J., eds. Soil color. Madison, Soil Science Society of America, 1993. p.109125. (SSSA Special Publication, 31)

ROCHA, L.C. \& CARVALHO, V.L.M. Gênese e evolução dos solos na bacia do Córrego do Quebra, Gouveia - MG. In: SIMPÓSIO BRASILEIRO DE GEOGRAFIA FÍSICA APLICADA, 10., Rio de Janeiro, 2003. Anais. Rio de Janeiro, Universidade Federal do Rio de Janeiro, 2003. CD-ROM

RODRIGUES, R.R. \& GANDOLFI, S. Restauração de florestas tropicais: Subsídios para uma definição metodológica e indicadores de avaliação e monitoramento. In: DIAS, L.E. \& MELLO, J.W.V., eds. Recuperação de áreas degradadas. Viçosa, MG, Universidade Federal de Viçosa, Sociedade Brasileira de Recuperação de Áreas Degradadas, 1998. p.203-215.
ROSA, E.C.; MALHEIROS, R.; SANTOS, A.C.; SOUZA, H.A. \& BARBOSA, A.S. Revegetação com espécies nativas do cerrado no parque ecológico de Goiânia. In: SIMPÓSIO BRASILEIRO DE RECUPERAÇÃO DE ÁREAS DEGRADADAS, 3., Ouro Preto, 1997. Trabalhos Voluntários. Viçosa, MG, Sociedade Brasileira de Recuperação de Áreas Degradadas, Universidade Federal de Viçosa, 1997. p.507-510.

RUGGieRO, P.G.C.; BATALHA, M.A.; PIVELLO, V.R. \& MEIRELLES, S.T. Soil-vegetation relationships in cerrado (Brazilian savanna) and semideciduous forest, Southeastern Brazil. Plant Ecol., 160:1-16, 2002.

SABATIER, D.; GRIMALDI, M.; PRÉVOST, M.F.; GUILLAUME, J.; GODRON, M.; DOSSO, M. \& CURMI, $P$. The influence of soil cover organization on the floristic and structural heterogeneity of a Guianan rain forest. Plant Ecol., 131:81-108, 1997.

SALOMÃO, F.X.T. \& QUEIROZ NETO, J.P. Dinâmica hídrica dos solos de Bauru (São Paulo- Brasil) aplicada ao manejo. In: CONGRESSO LATINOAMERICANO DE CIÊNCIA DO SOLO, 13., Águas de Lindóia, 1996. Anais. Águas de Lindóia, Sociedade Brasileira de Ciência do Solo, Sociedade Latinoamericana de Ciência do Solo, 1996. CDROM

SANTOS, J.C.L.; GRIMALDI, M.; CURMI, P.; HALLAIRE, V. \& CASTRO, S.S. Comportement hydrodynamique de sols sur grès au Brésil: conséquences sur la pédogenèse et le relief. In: WORLD CONGRESS OF SOIL SCIENCE, 16., Montpellier, 1998. Proceedings. Montpellier, International Soil Science Society, 1998. CD-ROM

SCHWERTMANN, U. Relations between iron oxides, soil color, and soil formation. In: BIGHAM, J.M. \& CIOLKOSZ, E.J., eds. Soil color. Madison, Soil Science Society of America, 1993. p.51-69. (SSSA Special Publication, 31)

SEYFRIED, M.S. \& MURDOCK, M.D. Response of a new soil water sensor to variable soil, water content, and temperature. Soil Sci. Soc. Am. J., 65:28-34, 2001.

TRIANTAFILIS, J.; WARD, W.T.; ODEH, I.O.A. \& McBRATNEY, A.B. Creation and interpolation of continuous soil layer classes in the lower Namoi Valley. Soil Sci. Soc. Am. J., 65:403-413, 2001.

van GENUCHTEN, M.T. A closed-form equation for predicting the hydraulic conductivity of unsaturated soils. Soil Sci. Soc. Am. J., 44:892-898, 1980.

VELOSO, H.P.; RANGEL FILHO, A.L.R. \& LIMA, J.C.A. Classificação da vegetação brasileira, adaptada a um sistema universal. Rio de Janeiro, Fundação Instituto Brasileiro de Geografia e Estatística, Departamento de Recursos Naturais e Estudos Ambientais, 1991. 124p.

VIEIRA, S.R. Permeâmetro: Novo aliado na avaliação de manejo do solo. O Agronômico, 47-50:32-33, 1995/1998. 